\title{
PANORAMA DAS PESQUISAS EM EDUCAÇÃO A DISTÂNCIA RELACIONADOS ÀS BIBLIOTECAS
}

\author{
Ligia Leite Castelli Ferreira \\ Mestranda do PPG em Ciência, Tecnologia e Sociedade - UFSCar \\ ligiacastelli@gmail.com
}

\section{Resumo}

\begin{abstract}
O objetivo deste estudo é fazer uma investigação do tema biblioteca para compreender em que medida a Educação a Distância tem se dedicado às pesquisas sobre biblioteca, a partir do Simpósio Internacional de Educação a Distância (SIED). Para tanto, foi feita a revisão sistemática dos artigos publicados nos anais do SIED dos anos de 2012, 2014 e 2016 . A análise foi feita com a leitura dos 749 resumos e, em alguns casos, com a leitura na íntegra dos artigos para o detalhamento dentro dos grupos temáticos, independente da forma de apresentação no SIED (comunicação oral ou cartaz). Os trabalhos do SIED foram sistematizados e apresentados em cinco grupos temáticos, que resultaram neste artigo.
\end{abstract}

Palavras-chave: Educação a Distância; Biblioteca para EaD; Produção Científica.

\section{INTRODUÇÃO}

$\mathrm{O}$ investimento em desenvolvimento e educação continua sendo um diferencial competitivo para as universidades. A Educação a Distância $(\mathrm{EaD})$ pode ser analisada como uma possibilidade na construção de mecanismos que favoreçam a aprendizagem e qualificação contínua de docentes, discentes e técnicos administrativos, podendo se realizar no decurso da vida. A expansão da $\mathrm{EaD}$ no âmbito internacional e no Brasil tem suscitado a ampliação quantitativa de pesquisas científicas com diferentes abordagens teóricas, que buscam compreender a modalidade, suas possibilidades, potencialidades e resultados.

$\mathrm{O}$ recente crescimento da $\mathrm{EaD}$ perpassa mudanças educacionais, econômicas e sociais com o desenvolvimento de tecnologias digitais e o desafio de educar uma sociedade que requer adaptação às novidades e à capacidade de aprender ao encontrar novas formas de construir conhecimento. A EaD precisou desenvolver estratégias pedagógicas investindo na formação profissional na busca para encontrar mecanismos que possam qualificar a educação. É essencial planejar e implementar sistemas de avaliação institucional contínua, a fim de apoiar o aprimoramento da gestão e da qualidade da educação (Brasil, 2007). Nesse contexto, a $\mathrm{EaD}$ precisou construir mecanismos que favorecessem a aprendizagem e a qualificação contínuas ao longo da vida em condições adequadas para o ensino superior.

Neste contexto, segue-se na defesa de que a biblioteca é um equipamento essencial de apoio, desenvolvimento e aprimoramento da qualidade na formação de alunos e docentes da modalidade a distância, seja para provê-los com conteúdos sistematicamente selecionados e organizados para fins de ensino e aprendizado, seja para supri-los com os produtos e serviços especializados voltados ao desenvolvimento de pesquisa. Deste modo, foi identificada a necessidade de averiguar em que medida a biblioteca tem sido objeto de investigação e pesquisa por aqueles que investigam e publicam sobre a EAD no Brasil. O objetivo é fazer uma análise partindo do ponto de vista da $\mathrm{EaD}$, ou seja, em que medida a EaD tem se dedicado a investigações sobre biblioteca. Nesse momento, não é objetivo deste trabalho analisar a produção científica sobre a $\mathrm{EaD}$ na área da Biblioteconomia e Ciência da Informação, uma vez que esses trabalhos já tem sido feitos com alguma frequência ${ }^{1}$.

\footnotetext{
${ }^{1}$ GARCEZ, Eliane Maria Stuart; RADOS, Gregório Jean Varvakis. Biblioteca híbrida: um Ciência da Informação, v. 31, n. 2, 2002.
} 
Assim, uma análise da produção científica a partir dos anais do SIED, dos anos de 2012, 2014 e 2016 foi realizada. O estudo buscou fazer um levantamento de quantos trabalhos foram publicados, quais os temas mais pesquisados e, em quais eixos temáticos em que se inseriram os artigos científicos, procurando identificar e analisar os conteúdos relacionados às bibliotecas. Em relação a importância de se analisar trabalhos de evento científico, segundo Campello (2000, p. 59-61), eventos científicos reúnem membros de uma comunidade científica para divulgar e discutir suas pesquisas, envolvendo um processo de avaliação por pares ou colegas, que permite o aperfeiçoamento dos trabalhos. Na velocidade em que as mudanças ocorrem na $\mathrm{EaD}$ é fundamental saber em que temas as pesquisas concentram um exame pormenorizado das potencialidades e dificuldades da modalidade a distância.

\section{MÉTODO DE PESQUISA}

Analisar a produção científica publicada em evento científico permite verificar seu desenvolvimento, temas mais investigados e menos pesquisados. Assim, a amostra foi composta por 749 resumos dos artigos científicos, sendo 182 artigos do SIED de 2012, 225 artigos do SIED de 2014 e 342 artigos do SIED de 2016. Neste estudo, o objetivo específico foi verificar nos cinco grupos temáticos (Grupo 1 - Gestão e estrutura da EaD; EaD e sociedade; Qualidade na EaD e a democratização do conhecimento; Grupo 2 Docência na EaD; Educação e tecnologias: formação e atuação de educadores/ profissionais; Grupo 3 - Aprendizagem na EaD; Ensino-aprendizagem aberto, flexível e a distância; e $\mathrm{O}$ estudante da $\mathrm{EaD}$ em foco; Grupo 4 - Tecnologias na EaD; Inovação em Educação e Tecnologias Digitais e Grupo 5 Pesquisa e produção do conhecimento em educação, tecnologias e linguagens) qual tema apresentou maior número de trabalhos, analisando possíveis razões para as ocorrências, e ao final apresentar os artigos científicos encontrados que trataram do tema biblioteca como apoio para $\mathrm{EaD}$.

2 O link para o SIED 2012 é

http://sistemas3.sead.ufscar.br/ojs/index.php/sied/i ndex. O link para o SIED 2014 é http://www.sied-
A análise foi feita com a leitura dos resumos e, em alguns casos, com a leitura na íntegra dos artigos para o detalhamento dentro dos eixos temáticos, independente da forma de apresentação no SIED (comunicação oral ou cartaz). Primeiro, optou-se por fazer a análise dos dados por ano de evento realizado, primeiro o ano de 2012, depois 2014 e, por fim 2016. Os artigos foram classificados em grupos e subgrupos, que gerou grupos temáticos expressos em cinco quadros e suas respectivas análises. Em um segundo momento, o tema biblioteca para $\mathrm{EaD}$ foi priorizado.

O SIED realizou três edições na Universidade Federal de São Carlos, organizado em duas etapas, uma virtual e outra presencial. Na etapa virtual o participante teve a possibilidade de acessar um ambiente virtual no Moodle, especialmente configurado para o Simpósio, que ofereceu a programação das webconferências, a lista das palestras e salas virtuais para discussão. Na etapa presencial, em geral foram dois ou três dias de palestras com membros de universidades brasileiras, palestrantes estrangeiros e pesquisadores com experiência em EaD do Canadá, Espanha, Estados Unidos e Portugal. O SIED possui um endereço eletrônico para cada ano de realização do evento com textos completos dos artigos. $^{2}$

Em 2012, as áreas de pesquisa no SIED foram divididas em quatro eixos temáticos: gestão, docência, aprendizagem e mediação tecnológica e pedagógica, com o tema "Reflexões pela democratização do conhecimento de qualidade". Já em 2014, o SIED adotou seis eixos temáticos: 1. Processo de ensino-aprendizagem aberto, flexível e a distância; 2. Pesquisa e produção do conhecimento em educação, tecnologias e linguagens; 3 . O estudante da $\mathrm{EaD}$ em foco; 4. Inovação em Educação e Tecnologias Digitais; 5. Qualidade na EaD e a democratização do conhecimento e 6. Educação e tecnologias: formação e atuação de educadores/ profissionais. Em 2016, no SIED também foram seis eixos temáticos: 1. Gestão $\mathrm{EaD}$ e questões mais amplas; 2. Inovação e Tecnologias para Educação; 3. Aprendizagem

enped2014.ead.ufscar.br/ojs/index.php/2014/index e o link para o SIED 2016 é http://www.siedenped2016.ead.ufscar.br/ojs/index.php/2016/. 
$(\mathrm{EaD}$ e Tecnologias de Informação e Comunicação); 4. Docência (EaD e Tecnologias de Informação e Comunicação formação de professores); 5. Docência (EaD e Tecnologias de Informação e Comunicação aspectos amplos) e 6. Aplicações e propostas $(\mathrm{EaD}$ e Tecnologia de Informação e Comunicação).

Ao considerar os objetivos da análise, optou-se por realizar análise exaustiva dos artigos com a leitura dos resumos dos 749 artigos científicos para poder categorizá-los. Com base no quadro 1 apresentado no tópico Apresentação e Discussão dos Resultados foi conduzida uma análise temática dos trabalhos publicados, a partir das informações presentes nos resumos. Em seguida, esses dados foram assentados por ano de edição do SIED e totalizados nos três eventos analisados. O quadro 1 apresenta a distribuição do número de artigos científicos por grupo temático e suas subdivisões. Inicialmente, vale ressaltar o crescimento do número de artigos aprovados e apresentados no SIED 2016. No SIED 2014 foram 225 artigos apresentados e 342 no SIED 2016, esse aumento global de artigos apresentados possivelmente se relaciona com as atividades de pesquisa na área acompanhando o que se observa na literatura internacional.

Segundo Bardin (1977, p.95) citada por Trivinos (1987, p.161) existem três etapas estabelecidas para o trabalho de análise de conteúdo: pré-análise, descrição analítica e interpretação referencial. A pré-análise: a organização do material, no caso desta préanálise nos artigos publicados no SIED dos anos de 2012, 2014 e 2016, na construção de um quadro para saber quais temas mais pesquisados. Na descrição analítica, formulouse a seguinte pergunta: quantos trabalhos relacionados ao tema biblioteca para $\mathrm{EaD}$ nos anos de 2012, 2014 e 2016 o SIED apresentou?

$\mathrm{Na}$ terceira etapa, a interpretação referencial, revelou a interpretação dos dados apresentados nos cinco quadros. A análise de conteúdo de Bardin (1977) foi escolhida porque ofereceu diferentes possibilidades de organização descritiva do conteúdo, que resultou em flexibilidade referente a aproximação ou o distanciamento dos artigos analisados nos eixos temáticos analisados. A análise de conteúdo de Bardin (1977, p.21) como método pode ser utilizado tanto na pesquisa quantitativa como na investigação qualitativa, mas com aplicações diferentes, sendo que na primeira, o que serve de informação é a frequência com que surgem certas características do conteúdo, enquanto na segunda é a presença ou a ausência de uma dada característica de conteúdo ou de um conjunto de característica de determinado fragmento de mensagem que é levado em consideração. Neste panorama de pesquisa utilizou-se a frequência com que surgiram os temas nos três anos de evento 2012, 2014 e 2016 para poder classificar os artigos científicos dentro dos eixos temáticos e suas subdivisões.

Na continuidade da análise do SIED 2012, o caminho escolhido foi a utilização dos quatro eixos predominantes em número de ocorrências da leitura dos resumos: docência na $\mathrm{EaD}$; formação de professores; tecnologia em $\mathrm{EaD}$; aprendizagem na EaD. Para classificar a produção científica do SIED de 2012, 2014 e 2016 foi utilizado o conjunto de categorias apresentado no quadro1. Isto é, ao fazer a leitura dos resumos dos artigos, eles foram sendo classificados de acordo com seus temas. Nestes três anos analisados, os trabalhos foram divididos em Grupos e Subgrupos temáticos conforme apresentado no quadro $1 \mathrm{e}$, em seguida, analisados por grupo temático de acordo com o subgrupo que se destaca por possuir maior número de artigos.

\section{APRESENTAÇÃO E DISCUSSÃO DOS RESULTADOS}

A trajetória percorrida nas três edições do evento, mesmo dentro do universo limitado do SIED, aponta para algumas constatações. Primeiramente, cabe salientar que com a leitura de todos os resumos do SIED 2012, foi encontrada apenas uma ocorrência com o tema biblioteca, o artigo "Análise do blog da Biblioteca Setorial de Ciências Agrárias e sua proposta como ferramenta comunicacional com os seus usuários", em que descreve a implantação do blog da Biblioteca Setorial de Ciências Agrárias como ferramenta de comunicação entre Biblioteca e usuários com intuito de aproximá-los para poder divulgar serviços, produtos na disseminação de assuntos relacionados ao contexto da biblioteca. Apesar de aparecer apenas uma ocorrência com o tema biblioteca no SIED 2012, ainda é possível destacar o artigo "A Produção Científica na Educação a Distância: um olhar sob o Curso de Licenciatura em 
Pedagogia da Universidade Federal de São Carlos" por abordar as políticas de incentivo à produção científica à distância com um mapeamento do Programa Unificado de Iniciação Científica e Tecnológica da UFSCar, trabalho de pesquisa que traz consigo a preocupação na formação do aluno pesquisador e se relaciona com o tema biblioteca para $\mathrm{EaD}$ porque universitários a distância precisam de produtos e serviços de biblioteca especialmente desenvolvidos para atendê-los para ter infraestrutura de apoio em suas pesquisas.

O Quadro 1 abaixo mostra os trabalhos pertencentes ao Grupo 1 - Gestão e estrutura da $\mathrm{EaD}$, que aglutinou os temas $\mathrm{EaD} \mathrm{e}$ sociedade e Qualidade na $\mathrm{EaD} e$ a democratização do conhecimento.

Quadro 1: Divisão dos artigos dos SIED divididos em grupos e subgrupos do Grupo 1

\begin{tabular}{|c|c|c|c|c|}
\hline & 2012 & 2014 & 2016 & $\begin{array}{l}\text { Totais dos } \\
\text { subgrupos }\end{array}$ \\
\hline $\begin{array}{l}\text { Grupo } 1 \text { - Gestão e estrutura da EaD, Grupo } 5 \text { - EaD e sociedade } \\
\text { (2012) e Grupo } 5 \text { - Qualidade na EaD e a democratização do } \\
\text { conhecimento (SIED } 2014 \text { e 2016) }\end{array}$ & & & & \\
\hline $\begin{array}{l}\text { 1.1 Institucionalização e reestruturação organizacional (2012)/ } 5.4 \\
\text { Gestão e institucionalização da EaD: estratégias e desafios (2014) }\end{array}$ & 5 & 10 & 15 & 30 \\
\hline 1.2 Planejamento, organização e financiamento & 3 & & & 3 \\
\hline $\begin{array}{l}\text { 1.3 Gerenciamento, controle de qualidade e difusão/ 5.3 Diretrizes e } \\
\text { referenciais de qualidade (SIED 2012) }\end{array}$ & 2 & & 4 & 6 \\
\hline 1.4 Polos de apoio presencial & 7 & & 2 & 9 \\
\hline $\begin{array}{l}\text { 1.5 Desafios, estratégias e dificuldades/ } 5.5 \text { Desafios, estratégias e } \\
\text { dificuldades }\end{array}$ & 13 & & & 13 \\
\hline 1.6 EaD: questões tecnológicas, econômicas e sociais & & 8 & 3 & 11 \\
\hline $\begin{array}{l}\text { 1.7 A EaD como estratégia de democratização no ensino superior: } \\
\text { acesso e equidade }\end{array}$ & & 5 & 2 & 7 \\
\hline $\begin{array}{l}\text { 1.8 Função social da EaD: trabalho, cidadania e emancipação } \\
\text { (subgrupo } 5.4 \text { de 2012) }\end{array}$ & 9 & & 1 & 10 \\
\hline $\begin{array}{l}\text { 1.9 Democratização, universalização e interiorização da formação e } \\
\text { do conhecimento (subgrupo } 5.1 \text { do SIED 2012) }\end{array}$ & 12 & & 7 & 19 \\
\hline Total parcial do Grupo 1 & 51 & 23 & 34 & 108 \\
\hline
\end{tabular}

No grupo 1, Gestão e estrutura da $\mathrm{EaD}$, que abrangeu o Grupo 5 - EaD e sociedade de 2012 e o Grupo 5 - Qualidade na $\mathrm{EaD}$ e a democratização do conhecimento (SIED 2014 e 2016) verificou-se a predominância do subgrupo $1.1 \quad$ Institucionalização $\mathrm{e}$ reestruturação organizacional, que em 2014, passou a ser chamado de Gestão e institucionalização da $\mathrm{EaD}$ : estratégias e desafios, correspondendo a $4 \%$ do total de 749 artigos avaliados, totalizando 30 artigos. Ou seja, 27,7\% dos artigos do grupo temático 1.1. Isto pode indicar que o termo "Gestão e institucionalização da EaD" incorporou muitos pontos de investigação dos pesquisadores envolvidos. Por outro lado, dos 30 artigos do subgrupo 1.1 Institucionalização e reestruturação organizacional, 16 deles $(2$ de 2012; 8 de 2014; 6 de 2016) trataram da questão da institucionalização da $\mathrm{EaD}$ no Brasil ao trazer em seu título termo relacionado ao tema ou ainda relataram como foi a experiência da institucionalização da $\mathrm{EaD}$ nas instituições de ensino superior ao compartilhar a introdução da modalidade nas estruturas organizacionais com diferentes modos de inserção nas instituições de ensino superior, que ganhou destaque nas pesquisas devido a busca do entendimento das dificuldades para a institucionalização da EaD. Os outros 14 artigos dos 30 encontrados no subgrupo temático 1.1 Institucionalização e reestruturação organizacional (2012)/ 5.4 Gestão e institucionalização da EaD: 
Artigos de Revisão

estratégias e desafios (2014) apresentaram assuntos relacionados à $\mathrm{EaD}, \mathrm{EaD}$ no Brasil a institucionalização dos cursos de formação de professores, indicando que os autores deram mais atenção a estes três assuntos ao aprofundar as temáticas em foco.
Abaixo segue a divisão dos artigos classificados no Grupo 2 - Docência na EaD e nos subgrupos que serão analisados posteriormente.

Quadro 2: Divisão dos artigos dos SIED divididos em grupos e subgrupos do Grupo 2

\begin{tabular}{|c|c|c|c|c|}
\hline & 2012 & 2014 & 2016 & $\begin{array}{l}\text { Totais dos } \\
\text { subgrupos }\end{array}$ \\
\hline \multicolumn{5}{|l|}{$\begin{array}{l}\text { Grupo } 2 \text { - Docência na EaD, Grupo } 6 \text { - Educação e tecnologias: } \\
\text { formação e atuação de educadores/ profissionais (SIED } 2014 \text { e } \\
\text { 2016) e subgrupo } 5.2 \text { (SIED 2014). }\end{array}$} \\
\hline 2.1 Formação e saberes & 28 & & 3 & 31 \\
\hline 2.2 Práticas e estratégias pedagógicas dos diferentes agentes & 16 & & 7 & 23 \\
\hline $\begin{array}{l}\text { 2.3 Profissão docente, coletividade e condições de trabalho/ } 6.3 \\
\text { Profissionalização e condições de trabalho em EaD }\end{array}$ & 9 & 4 & 2 & 15 \\
\hline $\begin{array}{l}\text { 2.4 Planejamento, avaliação e acompanhamento/ } 5.2 \text { Planejamento } \\
\text { educacional, currículo e avaliação: (re) pensando propostas } \\
\text { pedagógicas (2014) }\end{array}$ & 15 & 10 & 16 & 41 \\
\hline 2.5 Desafios, estratégias e dificuldades & 4 & & 5 & 9 \\
\hline $\begin{array}{l}\text { 2.6 Conhecimentos e práticas: aprendizagem da docência e } \\
\text { desenvolvimento profissional }\end{array}$ & & 35 & 40 & 75 \\
\hline 2.7 Docência em EaD e trabalho coletivo: atores e processos & & 11 & 25 & 36 \\
\hline $\begin{array}{l}2.8 \text { Uso de tecnologias, processos formativos coletivos e } \\
\text { aprendizagens institucionais }\end{array}$ & & 27 & 29 & 56 \\
\hline Total parcial do Grupo 2 & 72 & 87 & 127 & 286 \\
\hline
\end{tabular}

No Grupo 2, Docência na EaD, Educação e tecnologias: formação e atuação de educadores/ profissionais (SIED 2014 e 2016) e subgrupo 5.2 do SIED 2014 verificou-se a predominância de artigos no subgrupo 2.6 Conhecimentos e práticas: aprendizagem da docência e desenvolvimento profissional, que correspondeu a $10 \%$ dos artigos avaliados. Do total de 286 artigos do Grupo 2, 75 deles foram classificados no subgrupo 2.6 Conhecimentos e práticas: aprendizagem da docência e desenvolvimento profissional, correspondendo a $26,22 \%$ do total de artigos do Grupo 2, isto ocorre porque conforme afirma Mill e Oliveira (2014) ao estudar em outras pesquisas articulações sobre $\mathrm{EaD}$ e a evolução da área no Brasil, o tema docência e desenvolvimento profissional constatou-se do mesmo modo a predominância de pesquisas relacionadas à docência, o que pode indicar uma linha de pensamento que entende o professor como centro dos processos de formação e principal agente de estratégias de ensino e aprendizagem.

Abaixo segue a divisão dos artigos classificados no Grupo 3 - Aprendizagem na $\mathrm{EaD}$ e nos subgrupos que serão analisados posteriormente. 
Artigos de Revisão

Quadro 3: Divisão dos artigos dos SIED divididos em grupos e subgrupos do Grupo 3

\begin{tabular}{|c|c|c|c|c|}
\hline & 2012 & 2014 & 16 & $\begin{array}{l}\text { Totais dos } \\
\text { subgrupos }\end{array}$ \\
\hline \multicolumn{5}{|l|}{$\begin{array}{l}\text { Grupo } 3 \text { - Aprendizagem na EaD, Grupo } 1 \text { - Ensino-aprendizagem } \\
\text { aberto, flexível e a distância (SIED } 2014 \text { e 2016) e Grupo } 3 \text { - O } \\
\text { estudante da EaD em foco (SIED } 2014 \text { e 2016) }\end{array}$} \\
\hline $\begin{array}{l}\text { 3.1 Caracterização do estudante virtual/ 3.1 Perfil e necessidades } \\
\text { formativas }\end{array}$ & 6 & 16 & 22 & \\
\hline $\begin{array}{l}\text { 3.2 Organização dos tempos e espaços de estudos/ 3.2 Estratégias de } \\
\text { estudo pela EaD: construção de espaços e tempos/ 5.2 Flexibilidade e } \\
\text { redimensionamento espaço temporal (SIED 2012) }\end{array}$ & 4 & 8 & 14 & 44 \\
\hline 3.3 Serviços de Apoio ao Estudante: estruturas, equipes e propostas & & 2 & & 2 \\
\hline 3.4 Autonomia, identidade e coletividade na aprendizagem virtual & & 6 & 3 & 9 \\
\hline 3.5 Flexibilidade, personalização e estilos de aprendizagem & 3 & & 2 & 5 \\
\hline 3.6 Acesso, equidade, evasão e permanência & 7 & & 7 & 14 \\
\hline 3.7 Desafios, estratégias e dificuldades & 7 & & 5 & 12 \\
\hline $\begin{array}{l}\text { 3.8 Educação híbrida: desafios e aproximações entre ed. presencial e } \\
\text { a distância }\end{array}$ & & 12 & 26 & 38 \\
\hline 3.9 Modelos, teorias e sistemas de EaD & & 8 & 14 & 22 \\
\hline $\begin{array}{l}\text { 3.10 EaD como estratégia de redução da distância entre a educação } \\
\text { formal e o trabalho }\end{array}$ & & 5 & 4 & 9 \\
\hline $\begin{array}{l}\text { 3.11 Infraestrutura organizacional e pedagógica em propostas } \\
\text { educacionais híbridas }\end{array}$ & & 1 & & 1 \\
\hline Total parcial do Grupo 3 & 27 & 58 & 97 & 182 \\
\hline
\end{tabular}

Fonte: dados da pesquisa

No Grupo 3, Aprendizagem na $\mathrm{EaD}$, que passaram a se chamar nos anos de 2014 e 2016, Ensino-aprendizagem aberto, flexível e a distância e unidos ao grupo 3 - O estudante da $\mathrm{EaD}$ em foco somaram 182 artigos dos quais dois subgrupos chamaram a atenção pela predominância, o subgrupo 3.1 Caracterização do estudante virtual/, também chamado de 3.1 Perfil e necessidades formativas com 44 artigos e o subgrupo 3.8 Educação híbrida: desafios e aproximações entre educação presencial e a distância com 38 artigos. Em relação ao subgrupo 3.1 Caracterização do estudante virtual ou 3.1 Perfil e necessidades formativas são 44 artigos de um total de 182 do Grupo 3, ou 24,17\% de artigos do grupo. Estes 44 estudos apresentaram uma perspectiva micro dos processos das estratégias de aprendizagem, das possibilidades do ensino virtual e do perfil do estudante.

Dos 22 artigos analisados do subgrupo 3.1 Caracterização do estudante virtual do ano
2016, 50\% deles trataram dos perfis dos alunos no âmbito das ações educativas intrínsecas aos cursos, uma interpretação possível é que os temas de pesquisa estejam voltados para as possibilidades práticas de execução. Estes dados se confirmam em um estudo realizado por Zawacki-Richter (2009), que afirmam a necessidade da ampliação de pesquisas sobre o papel da cultura e das diferenças culturais em cursos a distância, principalmente para cursos a distância oferecidos em todo o território nacional e outros ainda com alcance global. Os dados obtidos por Zawacki-Richter (2009, p.14) encontram um ponto em comum com esta análise, a de que novas investigações devem incluir estudos sobre aspectos interculturais, impacto das diferenças culturais na gestão, acesso, equidade, ética e sistemas de apoio ao estudante.

Abaixo segue a divisão dos artigos classificados no Grupo 4 - Aprendizagem na $\mathrm{EaD}$ e nos subgrupos que serão analisados posteriormente. 
Artigos de Revisão

Quadro 4: Divisão dos artigos SIED divididos em grupos e subgrupos do Grupo 4

\begin{tabular}{|c|c|c|c|c|}
\hline & 2012 & 2014 & 2016 & $\begin{array}{l}\text { Totais dos } \\
\text { subgrupos }\end{array}$ \\
\hline $\begin{array}{l}\text { Grupo } 4 \text { Tecnologias na EaD e Grupo } 4 \text { Inovação em } \\
\text { Educação e Tecnologias Digitais (SIED } 2014 \text { e 2016) }\end{array}$ & & & & \\
\hline 4.1 Concepção e produção de materiais didáticos & 9 & & 11 & 20 \\
\hline $\begin{array}{l}\text { 4.2 Repositórios, objetos de aprendizagem e redundância } \\
\text { de conteúdos }\end{array}$ & 3 & & 3 & 6 \\
\hline $\begin{array}{l}\text { 4.3 Padrões de qualidade e processos logísticos na } \\
\text { produção e distribuição dos conteúdos }\end{array}$ & 1 & & & 1 \\
\hline $\begin{array}{l}\text { 4.4 Multimídias: linguagens, signos e discursos em } \\
\text { textos, imagens, áudios, movimentos etc./ } 4.4 \text { Jogos e } \\
\text { outras mídias interativas na educação: desafios e } \\
\text { possibilidades }\end{array}$ & 9 & 22 & 39 & 70 \\
\hline 4.5 Desafios, estratégias e dificuldades & 10 & 0 & 0 & 10 \\
\hline $\begin{array}{l}\text { 4.6 Multidispositivos tecnológicos e múltiplas mídias } \\
\text { para educação: custos, desenvolvimento e aplicações }\end{array}$ & 0 & 9 & 3 & 12 \\
\hline 4.7 Acessibilidade, inclusão e tecnologias digitais & 0 & 7 & 10 & 17 \\
\hline $\begin{array}{l}\text { 4.8 Estratégias virtuais de apoio à formação: REA, } \\
\text { laboratórios, bibliotecas e outros recursos }\end{array}$ & 0 & 7 & 11 & 18 \\
\hline Total parcial do Grupo 4 & 32 & 45 & 77 & 154 \\
\hline
\end{tabular}

Fonte: dados da pesquisa

No Grupo 4, Tecnologias na EaD passou a se chamar Inovação em Educação e Tecnologias Digitais, nos Simpósios Internacionais de Educação a Distância dos anos de 2014 e 2016, apresentou total de 153 artigos, dos quais 70 artigos ou $45,75 \%$, quase metade deles, pertencem ao subgrupo 4.4 Multimídia: linguagens, signos e discursos em textos, imagens, áudios, movimentos etc., que depois passou a se chamar -4.4 Jogos e outras mídias interativas na educação: desafios e possibilidades. Dentro do Grupo 4, a categoria 4.4 obteve destaque com uma diferença considerável em relação às outras categorias porque apresentou 70 artigos, uma tendência observada por Moran (2005), no artigo Tendências da educação online no Brasil em que ele previu um crescimento constante da multimídia educacional no desenvolvimento de materiais multimídia, de jogos educacionais em ambientes virtuais para permitir a construção de simulações colaborativas de interação e aprendizagem. Os jogos e as mídias interativas na educação criam mecanismos para sensibilizar e instigar os alunos na busca pelo conhecimento. A utilização de jogos educativos como recurso auxiliar na aprendizagem promovido pelo ensino virtual dão a oportunidade de ampliar o potencial do uso de imagens, animações e interatividade, além de resgatar o aspecto lúdico e prazeroso da aprendizagem (HAGUENAUER et al, 2007).

Uma possível interpretação é a de que o aumento das pesquisas na categoria jogos e mídias interativas na educação vem seguindo a evolução das estratégias de ensino cada vez mais abrangentes com formas contemporâneas de linguagem para que o aluno tenha um ganho significativo de qualidade no processo ensino aprendizagem apoiado pela Internet, consoante com a Lei de Diretrizes e Bases 9.394/96, que estabeleceu, em seu artigo $36, \S 1^{\circ}$, inciso III que o currículo deve proporcionar ao aluno, o conhecimento das formas contemporâneas de linguagem. Pesquisas desta natureza se fazem necessárias porque um estudo realizado pela Fundação Getúlio Vargas, Fundação DPaschoal, Movimento Todos pela Educação e Instituto Unibanco de 2006, chamada "Motivos para Evasão Escolar" (2009), constatou que 40,3\% dos jovens de 15 a 17 anos com renda familiar acima de $\mathrm{R} \$ 100,00$ per capita e que residem nas regiões 
metropolitanas de Salvador, Recife, Belo Horizonte, Rio de Janeiro, São Paulo e Porto Alegre deixam de estudar porque acreditam que a escola é desinteressante.
A seguir apresenta-se o Grupo 5 - Pesquisa e produção do conhecimento em educação, tecnologias e linguagens e as constatações a respeito deste grupo.

Quadro 5: Divisão dos artigos SIED divididos em grupos e subgrupos do Grupo 5

\begin{tabular}{|c|c|c|c|c|}
\hline & 2012 & 2014 & 2016 & $\begin{array}{l}\text { Totais dos } \\
\text { subgrupos }\end{array}$ \\
\hline $\begin{array}{l}\text { Grupo } 5 \text { - Pesquisa e produção do conhecimento em } \\
\text { educação, tecnologias e linguagens (grupo } 2 \text { do sied } \\
2014 \text { e sied 2016) }\end{array}$ & & & & \\
\hline 5.1 Redes colaborativas de pesquisa & 0 & 2 & 0 & 2 \\
\hline 5.2 EaD: tendências e temas silenciados na pesquisa & 0 & 7 & 4 & 11 \\
\hline $\begin{array}{l}\text { 5.3 Delimitação da área de conhecimento, qualidade } \\
\text { da pesquisa e modelos metodológicos }\end{array}$ & 0 & 0 & 0 & 0 \\
\hline $\begin{array}{l}\text { 5.4 Estratégias e instrumentos metodológicos na } \\
\text { coleta e análise de dados }\end{array}$ & 0 & 3 & 3 & 6 \\
\hline Total parcial do Grupo 5 & 0 & 12 & 7 & 19 \\
\hline $\begin{array}{l}\text { Total Geral (os } 5 \text { Grupos temáticos no SIED 2012, } \\
2014 \text { e 2016) }\end{array}$ & & & & 749 \\
\hline
\end{tabular}

Fonte: dados da pesquisa

O Grupo 5, Pesquisa e produção do conhecimento em educação, tecnologias e linguagens representaram 19 artigos ou 2,53\% do total de 749 artigos publicados. Uma pequena representatividade do Grupo 5, mas não menos importante porque revela a carência de estudos mais aprofundados sobre determinados aspectos da modalidade a distância. O subgrupo 5.2 EaD: tendências e temas silenciados na pesquisa destacou-se com 11 artigos ou 57,9\% dos artigos classificados no Grupo 5.

De modo geral no SIED de 2016, um dado positivo foi o percentual de trabalhos que mencionam a técnica de coleta de dados utilizada ou destacaram as questões metodológicas. Em uma amostragem de 20\% do total de 442 artigos publicados no SIED 2016, disponível no link http://www.siedenped2016.ead.ufscar.br/ojs/index.php/2016/i ssue/view/7 foram escolhidos os primeiros 88 artigos que apareceram nos anais de 2016 do SIED para verificar se indicavam a metodologia utilizada nas pesquisas. Dos 88 artigos analisados por amostragem, um fato positivo foi o alto percentual de trabalhos que mencionaram a metodologia utilizada ou até a técnica de coleta de dados, outras pesquisas ainda passaram a combinar técnicas de coleta de dados, como análise bibliográfica, a entrevista e o questionário, um total de $95,4 \%$ dos 88 artigos mencionaram a metodologia utilizada para realizar as pesquisas e apenas $4,6 \%$ do total não mencionaram as questões metodológicas.

O principal tópico a ser discutido neste capítulo consiste na mensuração do número de artigos com o tema biblioteca como apoio à EaD no SIED dos anos de 2012, 2014 e 2016. Por isso, após a análise dos trabalhos foram encontrados nas três edições do SIED quatro artigos que mencionaram a questão biblioteca, são eles: "Ambientes Virtuais de Aprendizagem e Educação Matemática Online: biblioteca interativa ou livro didático dinâmico", "Análise do blog da Biblioteca Setorial de Ciências Agrárias e sua proposta como ferramenta comunicacional com os seus usuários", "Biblioteca como equipamento de apoio a produção de conhecimento na Educação a Distância", "Uso de Recursos Educacionais Abertos na promoção do letramento informacional por bibliotecas da Rede Federal de Educação Profissional, Científica e Tecnológica".

No SIED de 2012 foi encontrado o artigo "Análise do blog da Biblioteca Setorial de Ciências Agrárias e sua proposta como ferramenta comunicacional com os seus usuários", em que descreve a implantação do 
blog da Biblioteca Setorial de Ciências Agrárias como ferramenta de comunicação entre Biblioteca e usuários com intuito de aproximá-los para poder divulgar serviços, produtos na disseminação de assuntos relacionados ao contexto da biblioteca. Conforme Giseli Castelani, autora do artigo, "o blog traz os usuários traz os usuários para o mundo da biblioteca e a biblioteca para o mundo de seus usuários." Este artigo trata do uso do blog como estratégia de comunicação na biblioteca, mas seu tema não abrange biblioteca como apoio ao ensino.

No ano de 2014 apareceu o artigo "Ambientes Virtuais de Aprendizagem (AVA) e Educação Matemática online: biblioteca interativa ou livro didático dinâmico". Este artigo traz a ideia de um ambiente virtual de aprendizagem em que não somente os materiais didáticos eram postados, mas também havia o registro das interações em um fórum entre professora e alunos na disciplina Álgebra Linear e se tornaram material didático. Um exemplo das interações mostra que o material elaborado previamente pela professora não atendia a dúvida de alguns alunos, mas com o registro das interações foi possível resolvê-las. Esse novo espaço de interação permitiu que os alunos descontextualizassem a mensagem e a contextualizassem em outras situações, que os autores chamaram de biblioteca interativa, já que a interação em rede pode se tornar um livro didático dinâmico ou uma biblioteca interativa.

$\mathrm{O}$ artigo "Ambientes Virtuais de Aprendizagem e Educação Matemática online: biblioteca interativa ou livro didático dinâmico" vislumbra um espaço configurado no ambiente virtual de aprendizagem conectado aos materiais didáticos para ajudar na aprendizagem de conceitos matemáticos construindo um movimento de apoio mútuo na aprendizagem chamado de biblioteca interativa. Uma ideia bastante interessante e que pode nortear o planejamento de disciplinas no ambiente de aprendizagem virtual, relacionando-se diretamente ao tema pesquisado biblioteca como apoio para o ensino a distância. Apesar de não ser um ambiente configurado como biblioteca, este artigo sobre educação matemática online mostra a preocupação com o tema biblioteca ao discutir as interações dos alunos com o professor a partir do material didático. Pode-se concluir que para os autores Chiari e Borba (2014), o local de discussão das dúvidas de conteúdo deve estar ligado à biblioteca interativa ou deve estar ligado a uma espécie de material didático.

No SIED 2016 dois artigos foram publicados com o assunto biblioteca: "Biblioteca como equipamento de apoio a produção do conhecimento na educação a distância" e "Uso de Recursos Educacionais Abertos na promoção do letramento informacional por bibliotecas da Rede Federal de Educação Profissional, Científica e Tecnológica". O primeiro artigo é fruto de um relatório técnico do grupo de pesquisa Pragma: Estudos Pragmáticos em Ciência da Informação (credenciado no $\mathrm{CNPq}$ ), da Universidade Federal de São Carlos, em que fazem parte da equipe alunos de iniciação científica, mestrado, doutorado, bibliotecários e dois técnicos de Imagem e Som. Os estudos do grupo de pesquisa Pragma apontam para a necessidade do desenvolvimento de produtos e serviços de informação destinados aos universitários a distância. O objetivo geral de analisar o desenvolvimento de ações de informação voltadas aos alunos da modalidade de EaD a fim de atender suas demandas de pesquisa se desdobra em objetivos específicos, que são: análise do contexto da produção de pesquisa de iniciação científica na $\mathrm{EaD}$, verificação dos comportamentos de busca da informação de alunos desta modalidade, diagnóstico e descrição das políticas que envolvem a criação, manutenção e uso de bibliotecas nos polos $\mathrm{EaD}$, verificação de quais ações desta natureza são desenvolvidas em âmbito internacional e apresentação do perfil das competências necessárias ao profissional da informação para atuar com este público.

Os resultados parciais das pesquisas do grupo Pragma indicam que variáveis precisam ser consideradas ao planejar e executar políticas de bibliotecas voltadas ao universitário a distância. Dentre os desafios da mediação tecnológica nas ações de informação estão políticas de desenvolvimento de coleções, acesso a conteúdo de base de dados, representação temática e descritiva de informações, serviços de referência virtual e estudo de usuários, dentre outros. Diante da urgência da criação de produtos e serviços de informação ao universitário a distância, a pesquisa desse artigo apresenta um conjunto de estudos que esclarece o quanto a biblioteca 
é demandada como equipamento de apoio na $\mathrm{EaD}$, mais especificamente no desenvolvimento de pesquisa de iniciação científica dos alunos EaD, em mapear qual o comportamento de busca ou competência informacional na busca e uso de fontes de informação; em como as bibliotecas dos polos tem atendido as necessidades informacionais destes estudantes; em aprofundar as investigações sobre como tem sido experiências fora do Brasil a este respeito e, por fim, a inquirição de como deve ser o profissional da informação, ou bibliotecário, que atua neste cenário.

Neste particular Gracioso (2016, p.05) conclui no artigo que:

Os resultados parciais de todas as frentes de pesquisa em andamento apontam para o fato desta modalidade de educação não enfatizar o desenvolvimento pesquisa de iniciação científica, o que justifica em alguma medida o pouco uso de produtos e serviços de informação (bibliotecas) por alunos desta modalidade. As experiências no exterior sugerem novas formas de participação da biblioteca na $\mathrm{EaD}$ e o profissional da informação precisará ainda conquistar este espaço de atuação no âmbito desta modalidade educacional.

O segundo artigo "Uso de Recursos Educacionais Abertos (REA) na promoção do letramento informacional por bibliotecas da Rede Federal de Educação Profissional, Científica e Tecnológica (RFEPCT)" encontrado no SIED 2016 analisa qual a colaboração do uso de recursos educacionais abertos em bibliotecas escolares na promoção do letramento informacional. Os movimentos a favor do acesso aberto tem propiciado discussões, que resultaram em diretrizes para produção e distribuição do conhecimento que se traduz na realidade em desenvolvimento de conteúdos, sistemas de busca e software com acesso aberto ao código fonte. Esses aspectos criam condições para a construção de repositórios institucionais, revistas digitais científicas e tecnológicas de acesso aberto podendo ser oferecidas aos usuários de bibliotecas escolares. $\mathrm{O}$ artigo defende a ideia de que na sociedade do conhecimento a informação deve ser tratada como um bem público e de acesso aberto, principalmente no que se refere à promoção do letramento informacional como estratégia virtual de apoio à formação escolar. Entretanto, os resultados do estudo mostram que, apesar dos profissionais bibliotecários reconhecerem $\mathrm{o}$ valor do uso de recursos educacionais abertos na promoção do letramento informacional ainda lhes falta conhecimento para uma prática efetiva à disponibilização dos recursos educacionais abertos exibidos nas páginas das bibliotecas pertencentes à RFEPCT da Região Centro-Oeste.

$\mathrm{Na}$ conclusão da análise apresentada referente aos três anos de realização do SIED parece haver uma lacuna na produção científica na $\mathrm{EaD}$ sobre o assunto biblioteca, uma vez que ao fazer a leitura dos 749 resumos dos artigos científicos apresentados nos anos de 2012, 2014 e 2016 foram encontrados somente quatro artigos científicos que se relacionam com o tema biblioteca. Assim, destes quatro trabalhos encontrados e analisados acima, apenas dois deles tratam diretamente do tema biblioteca como equipamento de apoio na $\mathrm{EaD}$. Os dois artigos encontrados foram "Ambientes Virtuais de Aprendizagem e Educação Matemática online: biblioteca interativa ou livro didático dinâmico" e "Biblioteca como equipamento de apoio a produção do conhecimento na educação a distância". Então, apresenta-se a constatação da lacuna de conhecimento apresentada no SIED dos anos de 2012, 2014 e 2016 em relação a falta de artigos científicos publicados com o conteúdo biblioteca para $\mathrm{EaD}$ em um evento científico considerado da área da Educação.

\section{CONSIDERAÇÕES FINAIS}

Os dados desta investigação indicam que o tema $\mathrm{EaD}$ e biblioteca é pouco pesquisado, afirmação confirmada por Mill e Oliveira (2014, p. 32) ao argumentar sobre a falta de estudos aprofundados nos diversos aspectos da modalidade a distância. Primeiro, há o fato da modalidade a distância ter se desenvolvido recentemente na realidade brasileira, em seguida, a primeira afirmação está aliada à complexidade da modalidade, que acaba por resultar na falta de aprofundamento em determinados temas de pesquisa na $\mathrm{EaD}$ porque os estudos apresentados não conseguem abranger todas as possibilidades de atuação da EaD. Apesar disso, neste levantamento há a constatação de que um dos assuntos que merece um estudo pormenorizado é biblioteca na $\mathrm{EaD}$, uma vez 
que dos 749 artigos científicos encontrados somente quatro se relacionam ao tema biblioteca.

Diante deste cenário, pode-se dizer que, na medida da evolução dos estudos sobre a EaD é possível redirecionar esforços em função dos objetivos das instituições interessadas em implementar novas propostas na oferta de produtos e serviços de biblioteca para universitários a distância. Pelos resultados obtidos não se pode afirmar que a pesquisa de biblioteca como apoio para $\mathrm{EaD}$ está consolidada, tanto pela quantidade de artigos encontrados na investigação (quatro de um total de 749 artigos científicos), quanto pelo aprofundamento das investigações, que demonstram uma lacuna de conhecimento a ser preenchida.

Assim, entende-se que, segundo Gatti (2001, p. 70) algumas considerações precisam ser feitas no que se refere à escolha das questões de pesquisa, para que não se tenham estudos somente de cunho utilitário com prevalência do aparente e do excessivamente limitado. Em outras palavras, não se deve fingir que problemas concretos existem no desenvolvimento da modalidade a distância em construção no Brasil. Na verdade é a busca incessante por questões de pesquisa adequadas que tragam importantes questionamentos é condição indispensável para o avanço da área, que inclui o conteúdo biblioteca na $\mathrm{EaD}$.

\title{
OVERVIEW OF RESEARCH IN DISTANCE EDUCATION RELATED TO LIBRARIES
}

\begin{abstract}
The purpose of this study is to do an investigation of the library theme to understand the extent to which distance education has been dedicated to research on library, from the International Symposium on Distance Education (SIED). For this reason, the systematic review of the articles published in the Annals of the SIED of the years 2012, 2014 and 2016 was carried out. The analysis was done with the reading of the 749 summaries and, in some cases, with the full reading of the articles for the detailing within the thematic groups, regardless of the form of presentation in the SIED (oral communication or poster). The work of the SIED was systematized and presented in five thematic groups, which resulted in this article.
\end{abstract}

Keywords: Distance Education. Distance Education for Libraries. Scientific Production.

\section{REFERÊNCIAS}

BERTAGNOLLI, S. C. et al. Bibliotecas Digitais Integradas a Ambientes Virtuais de Aprendizagem. RENOTE, v. 5, n. 2.

BRASIL. Ministério da Educação. 2007. Referenciais de Qualidade para Educação Superior a Distância. Disponível em: http://portal.mec.gov.br/seed/arquivos/pdf/leg islacao/refead1.pdf. Acesso em: maio 2017

CAMPELLO, B. S. Encontros científicos. In: Fontes de informação para pesquisadores e profissionais. Belo Horizonte: UFMG, 2000.

CHIARI, A. S. S.; BORBA, M. C. Ambientes Virtuais de Aprendizagem e Educação
Matemática online: biblioteca interativa ou livro didático dinâmico? In: SIED: EnPED SIMPÓSIO INTERNACIONAL DE EDUCAÇÃO A DISTÂNCIA E ENCONTRO DE PESQUISADORES EM EDUCAÇÃO A DISTÂNCIA, São Carlos: UFSCar, 2014.

FERREIRA, M.; CARNEIRO, T. C. J. A institucionalização da Educação a Distância no Ensino Superior Público Brasileiro: análise do Sistema Universidade Aberta do Brasil. Educação Unisinos, v. 19, n. 2, p. 228-242, 2015.

GATTI, B. A. Implicações e perspectivas da pesquisa educacional no Brasil 
contemporâneo. Cadernos de Pesquisa, $n$. 113, p. 65-81, 2001.

GRACIOSO, L. S. Biblioteca como equipamento de apoio a produção do conhecimento na educação a distância. In:

SIED: EnPED - SIMPÓSIO

INTERNACIONAL DE EDUCAÇÃO A DISTÂNCIA E ENCONTRO DE PESQUISADORES EM EDUCAÇÃO A DISTÂNCIA, 2016.

HAGUENAUER, C. J. et al. Uso de jogos na educação online: a experiência do LATEC/UFRJ. Revista EducaOnline, v. 2, n. $1,2007$.

LACERDA, A. L. et al. A importância dos eventos científicos na formação acadêmica: estudantes de biblioteconomia. Revista ACB, v. 13, n. 1, p. 130-144, 2008.

MILL, D.; OLIVEIRA, M. R.G. A Educação a Distância em pesquisas acadêmicas: uma análise bibliométrica em teses do campo educacional. Educar em Revista, n. 4, 2014.

MAIA, C.; MATTAR, J. ABC da EaD: a educação a distância hoje. 1. ed. São Paulo: Pearson Prentice Hall, 2007. 142 p.

NERI, M. et al. Motivos da evasão escolar. Brasília: Fundação Getúlio Vargas, 2009.
PETERS, O. A educação a distância em transição. São Leopoldo:UNISINOS, 2009. p.7-235.

QUIVY, R.; CAMPENHOUDT, Luc Van. Manual de Investigação em Ciências Sociais. Lisboa: Gradiva, 1998.

SAMPIERI, R. H.; COLLADO, C. F.; LUCIO, P. B. Metodología de la investigación. México: McGraw-Hill, 1991. SEVERINO, A. J. Metodologia do trabalho científico. 15 ed. São Paulo: Cortez, 1989. $238 \mathrm{p}$.

SILVA, S. S.; ZANIOLO, L. O. Identificando tendências temáticas divulgadas nos Anais do V Congresso Brasileiro de Educação Especial-UFSCar. In: SEMINÁRIO INTERNACIONAL INCLUSÃO EM EDUCAÇÃO EDUCAÇÃO ESPECIAL, 4., Rio de Janeiro, 2013. Rio de Janeiro:UFRJ. Anais... p. 790-799. Disponível em: http://www.lapeade.educacao.ufrj.br/anais/file s/WSMG2873.pdf. Acesso: maio 2017.

SOUZA, M. A. R. Uso de Recursos Educacionais Abertos no letramento informacional em bibliotecas de educação profissional. SIED: EnPED-Simpósio Internacional de Educação a Distância e Encontro de Pesquisadores em Educação a Distância, São Carlos: UFSCar, 2016.

TRIVINOS, A. N. S. Introdução à pesquisa em ciências sociais: a pesquisa qualitativa em educação. São Paulo: Atlas, 1987. p.161-173. 